\title{
The consequences of regular methamphetamine use in Tehran: qualitative content analysis
}

\author{
Javad Yoosefi Lebni ${ }^{1}$, Arash Ziapour ${ }^{2}$, Mostafa Qorbani ${ }^{3,4}$, Fereshteh Baygi ${ }^{5}$, Amin Mirzaei ${ }^{6}$, Omid Safari ${ }^{7}$, \\ Babak Rastegarimehr ${ }^{8}$, Bahar Khosravi ${ }^{9}$ and Morteza Mansourian ${ }^{10^{*}}$ (i)
}

\begin{abstract}
Background: In recent years, methamphetamine use has increased noticeably in Iran, and this can make harmful consequences for the health of individuals and society. Therefore, the study aimed to investigate the consequences of regular methamphetamine use in Tehran.

Methods: This study was conducted based on a conventional content analysis approach. Data were collected through observation and in-depth interviews with 20 regular adult users of methamphetamine in Tehran (including 15 males and 5 females). Participants were selected using snowball sampling and purposeful sampling, which continued until data saturation. Guba and Lincoln's criteria were used to assess the strength of the study.

Results: The extraction of the codes resulted in three main categories: (1)the short-term consequences, consisting of the sub-categories of individual and social consequences, (2) the long-term consequences, consisting of the subcategories of psychological and physical consequences, high-risk behaviors, severely decayed memory and changes in the eating pattern, and (3) hallucinations and delusions including the sub-categories of visual and auditory hallucinations, persecutory delusions and delusion of having supernatural power.

Conclusion: Regular methamphetamine use may have serious adverse effects on the overall health of individuals. It is therefore highly recommended that educational programs must implement with the use of methamphetamine in the high- risk groups in order to raise awareness and change attitudes about the short and long term consequences. is highly recommended.
\end{abstract}

Keywords: Methamphetamine, Regular users, Consequences, Qualitative study, Tehran

\section{Background}

Drug use is one of the most controversial issues in the field of social sciences [1,2], and dependence on it can be recognized as an illness, and the sociopolitical and health problems worldwide [3]. The drug consumption pattern has recently changed in Iran as the young generation is willing to consume new drugs such as

\footnotetext{
* Correspondence: mansourian55@gmail.com

${ }^{10}$ Health Management and Economics Research Center, Iran University of Medical Sciences, Tehran, Iran

Full list of author information is available at the end of the article
}

methamphetamine, crack, and heroin $[4,5]$. Methamphetamine is a stimulant drug [6], which has become popular in Iran with the name of crystal. It is the most frequently abused substance, and its prevalence in Iran is $5.2 \%$ of consumers [7]. Insurance companies are reluctant to pay the costs when they detect a psychiatric problem due to drug usage. Thus, the underreporting of drug use is a real problem [8-10]. The growth of methamphetamine consumption in the world [11] as well as in Iran has become an important problem for the

(c) The Author(s). 2020 Open Access This article is licensed under a Creative Commons Attribution 4.0 International License, which permits use, sharing, adaptation, distribution and reproduction in any medium or format, as long as you give appropriate credit to the original author(s) and the source, provide a link to the Creative Commons licence, and indicate if changes were made. The images or other third party material in this article are included in the article's Creative Commons licence, unless indicated otherwise in a credit line to the material. If material is not included in the article's Creative Commons licence and your intended use is not permitted by statutory regulation or exceeds the permitted use, you will need to obtain permission directly from the copyright holder. To view a copy of this licence, visit http://creativecommons.org/licenses/by/4.0/ The Creative Commons Public Domain Dedication waiver (http://creativecommons.org/publicdomain/zero/1.0/) applies to the data made available in this article, unless otherwise stated in a credit line to the data. 
health sector [12-14] at the individual and social levels $[15,16]$.

Ease of production, uncommon compounds, and different degrees of purity, low cost and high income, easy availability, simple and little needed equipment, the possibility of mass production, and difficulty in identifying laboratories make its trade very lucrative [17]. However, it can cause a lot of dangers, such as explosion, burns, lung burns and even cancer, for manufacturers and those who are near the places of production and exposed to waste $[18-20]$.

The regular methamphetamine use can lead to longterm harmful effects [21]. Ahmad Hatim [15] conducted a study on methamphetamine dependence in Malaysia, and the results showed that the prevalence of psychiatric co-morbidity among these people was $54.4 \%$, the prevalence of suicide was 12.1 , and $47.9 \%$ of these people had high levels of methamphetamine-induced psychosis.

Petit et al. [11], in their study, found that there was a significant association between methamphetamine addiction and personality disorders, and cardiovascular, pulmonary, infectious, and dental diseases. Sommers et al. conducted a study titled "Methamphetamine use among young adults: health and social consequences" and found that regular methamphetamine use was associated with the consequences of weight loss, seizures, and epilepsy. Besides, many methamphetamine abusers experienced severe psychological symptoms or diseases such as depression, hallucinations, paranoia, and violence [22]. Also, in a systematic review performed by Marshall and Warb, there was a strong association between methamphetamine use and increased depression, psychosis, and suicide mortality risk, but no association was found between methamphetamine use and infectious and dental diseases [23, 24].

The abuse of methamphetamine creates a sense of euphoria and lightness in a person, which is highly addictive. Methamphetamine rapidly enters the brain after taking and causes a sudden secretion of neurotransmitters including, norepinephrine, dopamine, and serotonin. The most important consequences of the use of this substance include obsessive-compulsive disorder [25], fetishism [26], depression [27], antisocial behavior [28, 29], violent behavior [30], movement disorders like Parkinson's disease [31], low mental health [32], insomnia [33], and risky sexual behavior [34].

Although many studies have been conducted on the side effects of methamphetamine worldwide, most of them have been carried out quantitatively, and experimentally. Crystal meth is produced in more different conditions in Iran [35]. Therefore, it has different effects from those of drugs produced in other countries. Also, since qualitative studies provide a better understanding of phenomena and can explain human beings' life experiences, interpretations, and perceptions following the cultural and social contexts $[36,37]$, there is a need for qualitative research in this field. Therefore, this study was conducted based on a qualitative content analysis approach aimed at exploring the consequences of regular methamphetamine use in Tehran.

\section{Methods}

\section{Design and sample}

This study was conducted based on a conventional content analysis approach. Content analysis is a qualitative research method used to analyze the data, and it is a systematic classification and coding technique aimed at a better understanding of the phenomenon under a study $[38,39]$.

The study population consisted of regular methamphetamine users in Tehran who had a history of methamphetamine use at least 3 months and had not previously used another drug. In-depth interviews and observation were used to collect the data. The first author of the paper only observed and noted the behaviors and physical symptoms of a regular methamphetamine user as a roommate without any intervention. Interviews were conducted by the first and eighth authors. In this study, considering the experience of the first author living with a regular methamphetamine user as a roommate for 5 months, his observations were coded and analyzed to record the behavior of that person. The study inclusion criteria were as follows: (1) regular methamphetamine use at the time of the study, (2) a history of regular methamphetamine use at least 3 months, (3) no history of the psychiatric disorder before methamphetamine use, (4) not being addicted to other drugs before or at the time of the study, and (5) the willingness to participate in the study. Regarding the subject of the research and the difficulty of sample identification, snowball sampling, and purposeful were used.

\section{Data collection and analysis}

In the present study, interviews were conducted with regular methamphetamine users in Tehran until data saturation was reached. Data saturation occurred when interviews were conducted with 20 people, including 15 men and 5 women. The codes obtained from the interviews were repeating, and the researchers ensured that no new codes were forming by continuing the interview. Then the theoretical saturation occurred, and the researcher interrupted the interview process because new information was not obtained by continuing the interview [40]. The duration of the interview was adjusted according to the willingness of the participant to answer the questions, which took an average of $40 \mathrm{~min}$.

At the beginning of each interview, demographic questions were asked, and then the interview continued with 
questions like: How did you feel when you use methamphetamine for the first time? What were the changes that had occurred in your body, personality, and personal and social behaviors due to short-term methamphetamine use (during the first 6 months)? What interesting things did you experience that you felt didn't happen to others during regular methamphetamine use? Explain the hallucinations you experienced after regular methamphetamine use. During the interviews, the full attention was paid to the appearance and body language of the participants for more comprehensive information. After each interview, the data were coded and analyzed.

After encoding and summarizing the data based on similarities and differences, the classification of codes was performed. The classes were compared together and ultimately. The themes were extracted by the analysis and interpretation of these data. Graneheim and Lundman's method was used to analyze the data [38]. In the first step, the whole content of the interview was transcribed into word by word and read several times until a general concept of the text was obtained. Then the text was divided into independent concepts and marked with specific codes. In the next step, the codes were divided into subcategories and classified according to similarities and differences. Finally, the hidden content was found and reported. An example of analysis and coding is given in Table 1.

Guba and Lincoln's criteria were used to assess the accuracy and rigor of the present study [41]. Regarding the credibility of the data, the authors had a prolonged engagement with the participants to win their trust and have a better perception of their experiences. In addition, the coding and analyzed results were forwarded to some of the participants to check if the results reflected their opinions and viewpoints (member check). To consider the transferability of the data, the obtained information was examined and approved by three specialists in the field of qualitative research and methamphetamine studies. The process of coding and data analysis was sent to them, and their comments were used to name the categories and sub-categories. Also, a comprehensive description of the subject was provided, and the direct quotations from participants were used.

\section{Ethics}

In this study, ethical considerations were made following the Helsinki Declaration. This study was approved by the Ethics Committee of Iran University of Medical Sciences. All subjects were informed about the study and provided the written informed consent. There was an emphasis on maintaining privacy and respecting the honesty in keeping and delivering the information accurately without mentioning the names of the people. Subsequently, participants were given the right to leave the interview at any time, if they wanted to leave the interview process, and they were promised to have the study results if they want.

\section{Results}

\section{Sample characteristics}

The results showed that the average age of the samples was $27 \pm 7.36$ years and the average duration of their drug use was $25 \pm 25.54$ months. Also, the majority of the sample were single and male and had earned a bachelor's degree (Table 2).

After analyzing the data, three main categories were identified that presented in Table 3; 1 . Short-term consequences, consisting of individual and social consequences, 2. Long-term consequences, consisting of physical, psychological, and behavioral consequences and decayed memory, 3. Illusions, consisting of visual and auditory illusions. Then quotes and other explanations are given.

\section{Short-term consequences}

Initially, regular methamphetamine use has associated with positive outcomes, such as increased concentration and sexual ability, but these positive outcomes are not sustainable, and after some time these positive effects are replaced by the negative outcomes, such as hallucinations, etc.

Consequences that appear to be beneficial which makes it more satisfactory to the person, but they are not sustainable.

\section{Individual consequences}

Regular methamphetamine use initially causes physical and psychological changes in an individual that can affect his or her behavior, and in some cases, these behaviors are appealing to a person.

Participant No. 7 said: "I got much more focused at the beginning of using the crystal. I studied less, but I learned more, and my grades were much better, I was very pleased with myself."

Table 1 An example of code analysis

\begin{tabular}{llll}
\hline Categories & Subcategories & Codes & Quotes \\
\hline Short-term & Individual & Enhancing & "The first month I was using crystal my sexual power was very good; I was pleased with \\
consequences & consequences & sexual ability & myself." \\
& Social & Getting more & "I was always an aloof person. My family always kept on at me about being isolated, but since I \\
& consequences & social & used crystal, I was not like that anymore, I got so socialized, and my family is pleased with me." \\
\end{tabular}


Table 2 Demographic information of the samples

\begin{tabular}{|c|c|c|c|c|c|}
\hline NO. & Age & Gender & Duration of drug use & Level of Education & Marriage status \\
\hline 1 & 25 & Male & 1 year & Bachelor's degree & Married \\
\hline 2 & 22 & Male & 9 months & High school diploma & Single \\
\hline 3 & 28 & Male & 2 years & Bachelor's degree & Single \\
\hline 4 & 33 & Male & 3 years & High school diploma & Married \\
\hline 5 & 18 & Male & 3 months & High school diploma & Single \\
\hline 6 & 30 & Male & 4 years & Bachelor's degree & Married \\
\hline 7 & 20 & Male & 1 year & High school diploma & Single \\
\hline 8 & 24 & Male & 1 year & Unfinished high school & Single \\
\hline 9 & 28 & Male & 9 months & Bachelor's degree & Single \\
\hline 10 & 32 & Male & 3 years & Unfinished high school & Single \\
\hline 11 & 29 & Male & 2 years & Bachelor's degree & Single \\
\hline 12 & 49 & Male & 10 years & Unfinished high school & Married \\
\hline 13 & 33 & Male & 1 year & Master's degree & Single \\
\hline 14 & 35 & Male & 3 years & Master's degree & Married \\
\hline 15 & 19 & Male & 10 months & High school diploma & Single \\
\hline 16 & 23 & Female & 1 year & High school diploma & Single \\
\hline 17 & 21 & Female & 2 years & Bachelor's degree & Single \\
\hline 18 & 28 & Female & 3 years & Bachelor's degree & Married \\
\hline 19 & 18 & Female & 8 months & Unfinished high school & Single \\
\hline 20 & 25 & Female & 2 years & Bachelor's degree & Married \\
\hline
\end{tabular}

Participant No. 1 said: "The first month I was using crystal, my sexual power was very good, I was pleased with myself." Participant No. 11 also said: "When I started to use crystal, I got stronger, and I lifted weights more than ever."

\section{Social consequences}

The short-term consumption of methamphetamine creates self-confidence in the person, and this changes the person's social behavior. Unfortunately, one of the features of methamphetamine is that it has positive effects on the early short-term period, which causes not to detect bad effects in a short period.

Participant No. 2 said: "I was always an aloof person. My family always kept on at me for being isolated, but since I used crystal, I was not like that anymore, I got so socialized, and my family is pleased with me."

Participant No. 9 said: "I was afraid of being in the crowd. I did not like to be at parties. If I went, I sat quietly, and do not say anything. But after starting using crystal, I felt more confident, I talk more in parties, and I like more to be with people."

\section{Long-term consequences of methamphetamine consumption}

Long-term consequences of methamphetamine consumption are more destructive than those of other substances, both in terms of physical and psychological consequences of this substance and. In fact, after a relatively short period of initial consumption, its harmful effects are observed which may lead to harm to the regular user or their family or even the society and completely disturb the life of the user.

\section{Physical consequences}

The effects of methamphetamine consumption in longperiod cause changes in the body of regular users, which can disrupt their life and endanger the health of the individual.

Participant No. 12 said: "My body always itches; sometimes I scratch my skin so much that it gets wounded and bleeds". Participant No. 10 also said: "All my teeth are rotten. I can hardly eat anything, whenever I eat my gums bleed".

Participant No. 4 also said: "I cannot sleep like before; my sleep is messed up; sometimes I cannot sleep at all."

\section{Psychological consequences}

Regular methamphetamine use causes mental changes in the regular user, which can disrupt his/her life.

Participant No. 18 said: "After a while using crystal, I got insouciant about everything, I do not care about anything. Nothing makes me happy or sad." Participant No. 20 said: "For a while, I think about suicide all the time. I 
Table 3 Categories, subcategories, and codes

\begin{tabular}{|c|c|c|}
\hline Categories & Subcategories & Codes \\
\hline \multirow[t]{2}{*}{$\begin{array}{l}\text { Short-term } \\
\text { consequences }\end{array}$} & $\begin{array}{l}\text { Individual } \\
\text { consequences }\end{array}$ & $\begin{array}{l}\text { Getting euphoric, getting happier, getting } \\
\text { stronger, getting more focused, } \\
\text { enhancing the sexual ability }\end{array}$ \\
\hline & Social consequences & $\begin{array}{l}\text { Getting more social, more acceptance in } \\
\text { the society, family happiness after the first } \\
\text { months of drug use }\end{array}$ \\
\hline \multirow[t]{5}{*}{$\begin{array}{l}\text { Long-term } \\
\text { consequences }\end{array}$} & $\begin{array}{l}\text { Physical } \\
\text { consequences }\end{array}$ & $\begin{array}{l}\text { Decayed and broken teeth, dry mouth, } \\
\text { sunken eyes, many wounds on the body } \\
\text { especially hands, wounded gums, many } \\
\text { pimples (under or over the skin) on the } \\
\text { face and chin, sleep decrease, having a } \\
\text { noisy sleep, pain, and burning of the } \\
\text { throat, getting thin. }\end{array}$ \\
\hline & $\begin{array}{l}\text { Psychological } \\
\text { consequences }\end{array}$ & $\begin{array}{l}\text { Depression, having irrational beliefs about } \\
\text { associates, thinking about suicide, getting } \\
\text { insouciant about everything, Obsessive- } \\
\text { Compulsive Disorder (OCD) }\end{array}$ \\
\hline & High-risk behaviors & $\begin{array}{l}\text { Doing dangerous activities like high- } \\
\text { speed driving, committing suicide, fight- } \\
\text { ing a lot, mistreating the spouse, loss of } \\
\text { control of behavior, high levels of vio- } \\
\text { lence against associates, wounding their } \\
\text { bodies, having sex with multiple people, } \\
\text { decrease of sexual power, getting } \\
\text { rougher in sex, Jumping from high alti- } \\
\text { tude due to lack of correct distance de- } \\
\text { tection, excessive talking, excessive anger. }\end{array}$ \\
\hline & $\begin{array}{l}\text { Highly decayed } \\
\text { memory }\end{array}$ & $\begin{array}{l}\text { Forgetting words while talking, forgetting } \\
\text { the names of relatives, breaking the } \\
\text { promise, keeping on at something, } \\
\text { missing the addresses many times, losing } \\
\text { different things like keys, forgetting the } \\
\text { password of the bank card, lack of focus. }\end{array}$ \\
\hline & $\begin{array}{l}\text { Changes in eating } \\
\text { pattern }\end{array}$ & $\begin{array}{l}\text { Excessive consumption of drinks } \\
\text { specifically soft drink, lack of tendency to } \\
\text { consume sour things like yogurt drink, } \\
\text { tendency to overeat sweats, lack of } \\
\text { balance in eating, eating less }\end{array}$ \\
\hline \multirow[t]{4}{*}{$\begin{array}{l}\text { Hallucinations } \\
\text { and delusions }\end{array}$} & Visual Hallucinations & $\begin{array}{l}\text { Seeing strange things, seeing things } \\
\text { other than their face in the mirror, the } \\
\text { illusion of believing in things that are not } \\
\text { real, the illusion of living with imaginary } \\
\text { people, having horns on the head in the } \\
\text { mirror, seeing someone sitting next to } \\
\text { the bed at night, seeing a little girl with } \\
\text { long hair, the illusion of seeing the } \\
\text { elephant while driving, seeing trees as } \\
\text { police officers, the illusion of seeing the } \\
\text { sea and the ship, the illusions of hitting } \\
\text { people by car (while they hit a cat), } \\
\text { seeing small ants on the arm, claiming to } \\
\text { see things that others cannot see, and } \\
\text { the illusion of attending a big concert }\end{array}$ \\
\hline & $\begin{array}{l}\text { Auditory } \\
\text { Hallucinations }\end{array}$ & $\begin{array}{l}\text { To hear the result of the football game } \\
\text { before it starts, to hear a voice } \\
\text { encouraging the person to commit } \\
\text { suicide, to hear the sound of walking feet } \\
\text { in the sleep, to hear strange noises }\end{array}$ \\
\hline & Persecutory Delusions & $\begin{array}{l}\text { Conspiracy of colleagues to kill them, } \\
\text { suspicion about spouse's betrayal, } \\
\text { suspicion about neighbors for the desire } \\
\text { to kill them, the illusion of being chased } \\
\text { by anonymous people, the illusion of an } \\
\text { individual coming to the room and } \\
\text { moving the thing, the illusion of being } \\
\text { harmed by others and the illusion of } \\
\text { cameras being in the houses they rented. }\end{array}$ \\
\hline & $\begin{array}{l}\text { The delusion of } \\
\text { having supernatural } \\
\text { power }\end{array}$ & $\begin{array}{l}\text { Believing in having the perfect sixth } \\
\text { sense and the illusion of predicting } \\
\text { everything (like results of soccer games) }\end{array}$ \\
\hline
\end{tabular}

think about how to kill myself." Participant No. 8 said: "I've been very obsessive-compulsive recently. When I want to do something, I think about it so much that I cannot do it, and its time passes."

\section{High-risk behaviors}

Long-term consumption of methamphetamine causes the regular user to show unpredictable behaviors that can endanger their own lives and others' lives, and may cause death to themselves or their associates.

Participant No. 6 said: "Recently, I've been fighting all the time. I beat my wife. I fight with my in-law family. I keep on at everyone."

Participant No. 10 said: "I have sex with many people, although I know it can be dangerous, I do it again." Participant No. 4 said: "I speak angrily to my wife every day; sometimes I beat her so much that I fear that she will die."

\section{Highly decayed memory}

Long-term consumption of methamphetamine leads to memory decay so that the person faces difficulty in doing regular activities.

Participant No. 8 said: "I forget my friends' names; I even confuse the names of my family members."

Participant No. 12 said: "I got very forgetful lately; I forget my password and give the wrong one."

Participant No 6 said: "Sometimes I miss my home address even though we have been living there for ten years."

Participant No. 12 said: "Sometimes it happens that I get myself busy doing something. Then I look at the clock and see that I only sit down for eight or nine hours getting busy with that idle thing."

\section{Changes in the eating pattern}

Long-term consumption of methamphetamine causes changes in nutrition patterns of eating and may lead to a tendency towards foods or drinks that were not consumed by them before.

Participant No. 20 said: "I used to love sour things a lot before, but since I started using crystal I do not like them, I'd love to eat sweet things and drink very much, too." Participant No. 19 said: "Since I started using crystal, my appetite has decreased, and I've been eating too little." Participant No. 13 said: "My eating is not balanced. I sometimes eat so much that my family gets worried. Sometimes it happens that I do not have anything for two days."

\section{Common hallucinations and delusions caused by the consumption of methamphetamine}

One of the common consequences of methamphetamine consumption is the creation of hallucinations and delusions in people, which sometimes causes violence against 
themselves and others, and may even result in murder and suicide.

\section{Visual hallucination}

Methamphetamine consumption causes visual hallucinations in regular users, such as claiming to see things that others cannot see.

Participant No 3 said: "In an evening that I was driving, I hit a cat with my car, but I thought I hit a person. For a while, I felt I was being chased. I hid."

Participant No. 10 said: "Sometimes I see tiny ants that march on my arm, so I scratch my arm until they all die."

Participant No. 16 said: "At night, a little girl comes and sits next to my bed, I say to my family, but they say there is nothing."

\section{Auditory hallucinations}

Methamphetamine consumption also results in auditory hallucinations, as many methamphetamine consumers claim to be able to hear voices that others cannot hear.

Participant No. 17 said: "Sometimes a voice keeps on at me that I should kill myself. I tried to kill myself a few times, but my family did not let me." Participant No. 3 said: "When I sleep, I hear feet that come close to me, but as I open my eyes, I see nobody. But when I close my eyes again, I hear the feet."

\section{Persecutory delusions}

Another problem that appears with the regular use of methamphetamine is the persecutory delusions. It makes a person pessimistic about others and may lead to being violent against them.

Participant No 12 said: "I always felt that my wife was betraying me, so I did not let her go out, and she was always under my observation, this caused us to fight, and I always beat her."

Participant No. 10 said: "I always feel that my colleagues want to kill me, once the butler wanted to put poison in my tea, but I understood it." Participant No. 7 said: "I feel like everyone wants me to die, they all want to kill me."

\section{Delusion of having supernatural power}

Methamphetamine consumption in some cases causes a person to claim to have supernatural powers and have a delusion of being associated with the universe.

Participant No. 9 said: "My sixth sense is perfect, and I can predict everything even the results of football matches, I feel someone comes to me before the game starts and tells me the result of the game."

Participant No. 11 said: "I can predict the upcoming events; I can even figure out who is about to die."

\section{Discussion}

This study aimed to explore the consequences of regular methamphetamine use in Tehran. The results showed that methamphetamine consumption in the short period is accompanied by individuals with the consequences of being happier, increased confidence, increased concentration, improved sexual power and social consequences such as getting more sociable, etc., leading to more desire to continue of the consumption, which was in line with results found by Kennedy [42], Bustani and Karamizadeh [43], Mohib Ali et al. [44], and Sia Johnny et al. [45]. However, our results showed that positive outcomes were replaced gradually by negative outcomes over time.

In Baangy et al.'s study, insomnia [32], and in Shakiba et al.'s study, an increase of excitement and concentration [13] have been identified as short-term consequences of methamphetamine consumption.

The positive short-term consequences of methamphetamine may cause the family to be more pleased with the individual, and it encourages the person to continue the use of methamphetamine. Since the families are more satisfied with the change in the person's behavior, they have less doubt that perhaps this change in behavior is due to methamphetamine consumption. But the regular use of methamphetamine, in the long run, is accompanied by extremely dangerous consequences for the individual and the society, which can disrupt the life of the individual and society.

According to the findings of this study, the physical and psychological consequences such as high-risk behaviors, decayed memory, and changes in the pattern of eating were among the sub-categories related to the consequences of long-term methamphetamine consumption. The results showed that long-term methamphetamine consumption would affect the human body and could have harmful effects on it, endangering the health of the individual and even leading to death. Previous studies reported the association between regular methamphetamine use, and human physical health, for example, the relationship between the methamphetamine abuse, oral dryness(dry mouth), cardiovascular diseases [46], infectious diseases such as endocarditis [47] and teeth decay $[48,49]$ has been proven in this area.

Psychological consequences such as depression, having irrational beliefs about associates, thinking about suicide, insouciance about everything, and obsessive-compulsive disorder are other effects of the long-term methamphetamine consumption in this study. The results of previous studies showed that the abuse of methamphetamine is associated with the sustainable psychological changes in regular users, such as depression, isolation, personal conflicts [50], irrational thoughts [51], and obsessive-compulsive disorder [28]. 
Another sub-category related to long-term consequences was high- risk behaviors. Long-term consumption of methamphetamine can change a person's behavior and increase high-risk behaviors [52]. Changes in behavior and an increase in risky behaviors are the symptoms of long-term regular use of methamphetamine. Violence, aggressiveness, and hostile attitudes are also common in methamphetamine users [53, 54]. Also, regular use of methamphetamine can increase the sexual need of an individual abnormally. Because of the other effects of this substance, it causes incontinence in a person, so that he no longer uses preventive measures and devices. And the person is forced to indulge in sexual activities with multiple people that can endanger the health of the person, leading to AIDS, hepatitis, and other sexually transmitted diseases [55-59].

Another symptom of long-term regular use of methamphetamine is memory disorder. Maxwell (2005) and Lundqvist (2005) found a significant relationship between the methamphetamine abuse and the decreased cognitive and psychosocial functioning in the individual $[59,60]$, which caused problems such as memory decrease, confusion, and forgetfulness [61, 62]. Continued use can also result in memory loss, and people with it resemble those who have Alzheimer's disease [63].

Changes in the pattern of eating are another subcategory of long-term consequences, which was a new finding that is not mentioned in other studies. Changes in eating patterns and excessive loss of appetite have to do with using methamphetamine so that regular users lose weight and suffer from malnutrition after a while [64].. However, the consequence of methamphetamine consumption may be attractive to some people. Maybe one of the main reasons for the tendency to methamphetamine, especially for women, is their decision for weight loss. As shown in previous studies, the weight of women who consume methamphetamine is significantly less than that of those who do not use it [65]. The results obtained from the study of Tsirigotis also showed that addicted women experienced more indirect selfdestructiveness than their addicted men [66].

Another consequence of regular use of methamphetamine is the hallucination and delusion in the users, which is not obtained from previous studies. These hallucinations and delusions sometimes lead to social harm and murder, which we see a title related to this issue (e.g. Crystal user Killed his Family) in the newspapers every day, and it increases day by day due to the increasing number of methamphetamine consumers. The common visual hallucinations that these people have included seeing things without real existence, and no one else can see these things except them. In some cases, users have the hallucination of seeing insects on their skin, which results in scratching and wounding their skin, which is why many people who are using this drug usually have a lot of wounds [23, 67]. In the studies of Baggott et al. and Akiyama, visual hallucinations caused by methamphetamine use were also reported [68, 69].

Auditory hallucinations are also observed in them, which sometimes stimulate the regular users to hurt themselves and others. Auditory hallucinations were also reported in methamphetamine-dependent in the study of Mahoney et al. [70].

Another form of hallucination and delusion in these people is the delusion of having supernatural power and can fight the whole world. It creates a kind of false selfconfidence in them. The majority of regular methamphetamine users believed that they have superhuman strength to do extraordinary things, such as predicting the future, and because these people saw themselves as safe in danger, they took dangerous actions and endangered their health.

But perhaps the worst kind of delusions in these people is the delusion of others' conspiracy against them [25]. Many regular methamphetamine users experience this delusion that others are thinking about harming them or their wives or husbands or plans to betray them. This type of delusion makes these people commit dangerous unpredictable behaviors. One of the new results in this study, which is not mentioned in previous studies, maybe due to differences in the composition of methamphetamine made of different compounds in Iran and having different effects. Sometimes the severity of these behaviors can be highly bothered for society. The results of the study of Mansourian et al. also showed that methamphetamine users have a suspicion about associates [67].

\section{Strengths and limitations}

This was the first Iranian study that addressed the consequences of regular methamphetamine use in Tehran, the capital city of Iran, employing a qualitative approach since first-hand information can be attained by doing so. Moreover, given that the first author of the present study experienced the lifestyle of his methamphetamine addicted roommate, the real behaviors of a regular methamphetamine user could be identified and recorded easily to some extent. Another strength of the study was the selection of subjects with no history of previous use of any other drugs except methamphetamine, which could help discover the specific consequences of regular methamphetamine use. However, there were some limitations, too. One of the main limitations was the difficulty of access to regular methamphetamine users, which was resolved by choosing an appropriate sampling method and drawing the trust of the samples to introduce their peer user friends. Another problem was 
determining the time and place of the interview, which was repeatedly changed by the participants. The researchers solved this problem by frequently visiting the places of the interview.

\section{Conclusion}

The harmful consequences of methamphetamine consumption can endanger the health of the individual, family, and society. Therefore, raising the knowledge about the short-term and long-term effects of regular methamphetamine use, its symptoms as well as providing appropriate programs to change attitudes toward the consequences can be an effective step in preventing the use of this drug. Besides, appropriate counseling to regular methamphetamine users and assisting their rehabilitation to return to a healthy life, are recommended to control the adverse effects caused by the use of this drug.

\section{Abbreviations \\ MH: Methamphetamine regular use; QCA: Qualitative Content Analysis}

\section{Acknowledgements}

All participants in this study are appreciated.

\section{Authors' contributions \\ All authors have made contributions to the paper and authorized submission. Javad Yoosefi lebni, Fereshteh Baygi, Arash Ziapour, Morteza Mansourian: Conception of study design, data analysis support, interpretation, drafting of the article and approved the final manuscript as submitted. Javad Yoosefi lebni, Arash Ziapour, Bahar Khosravi, Mostafa Qorbani: Data analysis, interpretation, drafting of the article, revisions, and approved the final manuscript as submitted. Amin Mirzaei, Omid Safari, Babk Rastegarimehr, Morteza Mansourian: Interpretation, critical review, and revisions, approved the final manuscript as submitted.}

\section{Funding}

The present study was supported by grant No (IR. IUMS. REC. 96-04-27-32610) from Vice-Chancellor for Research and Technology of Iran University of Medical Sciences.

\section{Availability of data and materials}

The datasets generated and analyzed during the current study are not Publicly available due to protect the participants' anonymity but are Available from the corresponding author on reasonable request.

\section{Ethics approval and consent to participate}

The study procedures were carried out following the Declaration of Helsinki. This study was approved by the Ethics Committee of Iran University of Medical Sciences (IR.IUMS.REC.1396.32610).

Informed consent was taken from all the participants. There was an emphasis on maintaining privacy in keeping and delivering the information accurately without mentioning the names of the participants. The participants were given the right to leave the interview at any time if they wished to leave the interview process, and they were promised to have the study results if they want.

\section{Consent for publication}

Not applicable.

\section{Competing interests}

The authors declare that they have no competing interests.

\section{Author details}

Health Education and Health Promotion, School of Health, Iran University of Medical Sciences, Tehran, Iran. ${ }^{2}$ Health Education and Health Promotion, Health Institute, Kermanshah University of Medical Sciences, Kermanshah, Iran. ${ }^{3}$ Non-Communicable Diseases Research Center, Alborz University of Medical Sciences, Karaj, Iran. ${ }^{4}$ Chronic Diseases Research Center, Endocrinology and Metabolism Population Sciences Institute, Tehran University of Medical Sciences, Tehran, Iran. ${ }^{5}$ Center of Maritime Health and Society, Department of Public Health, University of Southern Denmark, Esbjerg, Denmark. ${ }^{6}$ Public Health Department, llam University of Medical Sciences, Ilam, Iran. ${ }^{7}$ Departments of Pediatrics, School of Medicine, Alborz University of Medical Sciences, Karaj, Iran. ${ }^{8}$ Abadan Faculty of Medical Sciences, Abadan, Iran. ${ }^{9}$ Master of Women Studies, Shahid Madani University of Azerbaijan, Azerbaijan, Iran. ${ }^{10}$ Health Management and Economics Research Center, Iran University of Medical Sciences, Tehran, Iran.

Received: 23 December 2019 Accepted: 6 May 2020

Published online: 14 May 2020

\section{References}

1. Mansourian M, Abbas J, Qorbani M, Mehr BR, Ziapour A, Lebni JY, et al. Secrecy in Drug Abusers: A Qualitative Study in Iran. J Postgrad Med Institut. 2019;33(3):256-61.

2. Pelloux Y, Giorla E, Montanari C, Baunez C. Social modulation of drug use and drug addiction. Neuropharmacology. 2019;159:107545.

3. Singer M. Drugs and development: the global impact of drug use and trafficking on social and economic development. Int J Drug Policy. 2008; 19(6):467-78.

4. Sajjadi M, Shariatifar N, Matlabi M, Abbasnezhad A, Basiri K, Nazemi H. The rate of knowledge and attitude toward psychoactive drugs and its abuse prevalence in Gonabad University students. Horizon Med Sci. 2009;15(2):58-64.

5. Rezaei F, Noroozi A, Armoon B, Farhoudian A, Massah O, Sharifi H, et al. Social determinants and hepatitis $C$ among people who inject drugs in Kermanshah, Iran: socioeconomic status, homelessness, and sufficient syringe coverage. J Subs Use. 2017;22(5):474-8.

6. Dehghan M, Fazel A, Rezaee AM. Effectiveness of psychotherapy with matrix pattern on the glass drug craving. Indian J Health Wellb. 2017:8(2):113-9.

7. Zolfegharzadeh KM, Khalilzadeh MA, Ghoshooni M, Hashemian P. On the effectiveness of alpha-theta neurofeedback in craving for drug use among methamphetamine-dependent patients; 2016.

8. Akhteyari H. Addiction to glass. J Addict Med. 2013;1(2):9-12.

9. Jalali A, Yekzaman M, Bazrafshan M-R, Salari N, Rahmati M. Investigating the effect of family counseling on the acceptance and support of patients under methadone maintenance treatment. Shiraz E Med J. 2018;19(5): e62347.

10. Shojaezadeh D, Peyman N, Shakeri MT, Nedjat S, Hakkak AM, Taghdisi MH, et al. Pictorial health warning labels on cigarette packages: an investigation on opinions of male smokers. Iran Red Crescent Med J. 2014;16(3):e14879.

11. Petit A, Karila L, Chalmin F, Lejoyeux M. Methamphetamine addiction: a review of the literature. J Addict Res Ther. 2012:S1-6.

12. Nouri Khajavi M, Afghah S, Azizi-khoei A. Self-injury due to methamphetamine psychosis: a case report. Iran Rehabilit J. 2015;13(1):77-4.

13. Shakiba M, Shakiba J, Sharifi H, Shakiba M, Rafaiee R. The effect of life skills training in group and behavior change on affective health of people addicted to methamphetamine crystal. Zahedan J Res Med Sci. 2014;16(5): 6-10

14. Alam mehrjerdi Z, Barr AM, Noroozi A. Methamphetamine-associated psychosis: a new health challenge in Iran. DARU J Pharm Sci. 2013;21: 30-33.

15. Ahmad HS. Methamphetamine dependence in Malaysia: psychiatric comorbidity and suicidality, methamphetamine induced psychosis, genetic polymorphisms and efficacy of aripiprazole in the treatment of methamphetamine dependence/Ahmad Hatim Sulaiman: Univ Malaya; 2011.

16. Hakkak HRM, Taghdisi MH, Shojaezadeh D, Nedjat S, Peyman N, Taghipour A. Clarifying the role of schools in tendency or lack of tendency toward smoking among teenage boys (11-14) in Mashhad, Iran. Iran Red Crescent Med J. 2014;16(1):e12848.

17. Kiani M, Shamloo B, Sadeghi A. Prevention of psychotropic substance use by adolescents. Med J Q J. 2011;5(19):127-67. 
18. Ciccarone D. Stimulant abuse: pharmacology, cocaine, methamphetamine, treatment, attempts at pharmacotherapy. Primary Care: Clin Office Pract. 2011;38(1):41-58.

19. Bloom GR, Suhail F, Hopkins-Price P, Sood A. Acute anhydrous ammonia injury from accidents during illicit methamphetamine production. Burns. 2008:34(5):713-8.

20. Davidson SB, Blostein PA, Walsh J, Maltz SB, Elian A, VandenBerg SL. Resurgence of methamphetamine related burns and injuries: a follow-up study. Burns. 2013;39(1):119-25.

21. Anderson K. A model program for treating methamphetamine use among adolescents: Alliant Int Univ; 2018.

22. Sommers I, Baskin D, Baskin-Sommers A. Methamphetamine use among young adults: health and social consequences. Addict Behav. 2006;31(8): 1469-76.

23. Marshall BD, Werb D. Health outcomes associated with methamphetamine use among young people: a systematic review. Addict. 2010;105(6):9911002.

24. Farnia V, Alikhani M, Davarinejad O, Golshani S, Salemi S, Hookari S, et al. A discriminant analysis of psychological and brain-behavioural system features to predict methamphetamine dependence. NeuroQuant. 2019:17(8):24-32.

25. Shoaa KM. The relationship between emotional intelligence and recurrence of glass consumer consumers in Tehran. Soc Res Q. 2011;10:137-51.

26. Mehdizadeh-Zareanari A, Ghafarinezhad A, Soltani H. Fetishism due to methamphetamine (glass) abuse: a case report. Addict Health. 2013; 5(1-2):73

27. Brière FN, Fallu J-S, Janosz M, Pagani LS. Prospective associations between meth/amphetamine (speed) and MDMA (ecstasy) use and depressive symptoms in secondary school students. J Epidem Commun Health. 2012; 66(11):990-4.

28. Eslami-Shahrbabaki M, Fekrat A, Mazhari S. A study of the prevalence of psychiatric disorders in patients with methamphetamine-induced psychosis. Addict Health. 2015;7(1-2):37.

29. Shakeri J, Azimi M, Rezayi M, Abdoli N, Ghasemi SR. The evaluation of demographics, behavioral and psychiatric characteristics of methamphetamine abusers in detoxification and addiction control clinics related to Kermanshah University of Medical Sciences. Iran J Psychiatry Clin Psychol. 2010;16(3):305-6.

30. Compton WM III, Cottler LB, Jacobs JL, Ben-Abdallah A, Spitznagel EL. The role of psychiatric disorders in predicting drug dependence treatment outcomes. Am J Psychiatry. 2003;160(5):890-5.

31. McKetin R, Voce A, Burns R. Research into methamphetamine use in the Australian Capital Territory. Perth Australia: National Drug Res Instit. 2017.

32. Bungay V, Malchy L, Buxton JA, Johnson J, MacPherson D, Rosenfeld T. Life with jib: a snapshot of street youth's use of crystal methamphetamine. Addict Res Theory. 2006;14(3):235-51.

33. Hosseinifard SM, Ahmadian A, Smaeelifar N. The synergistic (MARATHON) effect of combined methamphetamine with sexual stimulant drugs on increasing the likelihood of high-risk sexual behaviors. Addict Health. 2014 6(3-4):112.

34. Lim SH, Akbar M, Wickersham JA, Kamarulzaman A, Altice FL. The management of methamphetamine use in sexual settings among men who have sex with men in Malaysia. Int J Drug Policy. 2018:55:256-62.

35. Lebni JY, Ziapour A, Qorbani M, Khosravi B, Mirzaei A, Safari O, et al. Explaining the causes of crystal addiction in Tehran: a qualitative approach. J Public Health. 2019:1-7

36. Speziale HS, Streubert HJ, Carpenter DR. Qualitative research in nursing: advancing the humanistic imperative: Lippincott Williams \& Wilkins; 2011.

37. Munhall P. A phenomenological method. PL Munhall (Ed), Nursing research: A Qualitat Perspect 2007:4:145-210.

38. Graneheim UH, Lundman B. Qualitative content analysis in nursing research: concepts, procedures and measures to achieve trustworthiness. Nurse Educ Today. 2004;24(2):105-12.

39. Yoosefi Lebni J, Mansourian M, Hossain Taghdisi M, Khosravi B, Ziapour A, Demir Özdenk G. A study of Kurdish women's tragic self-immolation in Iran: a qualitative study. Burns. 2019:45(7):1715-22.

40. Marshall MN. Sampling for qualitative research. Fam Pract. 1996;13(6): 522-6.

41. Lincoln YS, Guba E. Naturalistic inquiry London. England: Sage Publications; 1985.

42. Kennedy KM. The relapse cycles of female methamphetamine users; 2015
43. Bostani D, Karamizadeh A. Condition and strategy of glass consumption among addicted women (case study: Kerman city). Women Develop Politic. 2017;15(1):1-20.

44. Moheb Ali H, Qasam A, Mardani S. Measurement of the motivations leading to the use of industrial opiates (case study of caretakers in Qazvin). J Qazvin Law Enforcem Q. 2016:5(7):114-33.

45. Siah Jani L, Orki M, Zare H. Methamphetamine use time (glass) and persistent attention deficit disorders in methamphetamine abusers. J Drug Addict Res. 2014;27:53-66.

46. De Silva DA, Wong MC, Lee MP, Chen CL-H, Chang HM. Amphetamineassociated ischemic stroke: clinical presentation and proposed pathogenesis. J Stroke Cerebrovas Diseas. 2007;16(4):185-6.

47. Cooper HL, Brady JE, Ciccarone D, Tempalski B, Gostnell K, Friedman SR Nationwide increase in the number of hospitalizations for illicit injection drug use-related infective endocarditis. Clin Infect Diseas. 2007:45(9): 1200-3

48. Hasan AA, Ciancio S. Relationship between amphetamine ingestion and gingival enlargement. Pediatr Dentist. 2004;26(5):396-400.

49. Rhodus N, Little J. Methamphetamine abuse and" meth mouth". Northwest Dentis. 2005;84(5):29 31, 3-7.

50. Line N. Evaluation anger control training on individual and social adaptation of addicts. J Consult Develip. 2010;44(77):34-50.

51. Ghorbani M, Kazemi H, Ghorbani T. Comparing irrational beliefs in patients with crystal abuse disorder and ordinary people. Knowled Res Appl Psychology Autumn. 2011;12(3):32-7.

52. Neale A, Abraham S, Russell J. "Ice" use and eating disorders: a report of three cases. Int J Eating Disord. 2009;42(2):188-91.

53. Wilkins $C$, Reilly J, Rose E, Roy D, Pledger M, Lee A. The Socio-Economic impact of amphetamine type stimulants in New Zealand. Centre for Socia and Health Outcomes Research and Evaluation (SHORE) Massey University, Auckland. 2004

54. Hadland SE, Marshall BD, Kerr T, Qi J, Montaner JS, Wood E. Depressive symptoms and patterns of drug use among street youth. J Adol Health. 2011:48(6):585-90.

55. Colfax G, Vittinghoff E, Husnik MJ, McKirnan D, Buchbinder S, Koblin B, et al. Substance use and sexual risk: a participant-and episode-level analysis among a cohort of men who have sex with men. Am J Epidem. 2004; 159(10):1002-12.

56. Shoptaw S, Reback CJ, Freese TE. Patient characteristics, HIV serostatus, and risk behaviors among gay and bisexual males seeking treatment for methamphetamine abuse and dependence in Los Angeles. J Addict Diseas. 2001;21(1):91-105.

57. Reback CJ, Larkins S, Shoptaw S. Changes in the meaning of sexual risk behaviors among gay and bisexual male methamphetamine abusers before and after drug treatment. AIDS Behav. 2004:8(1):87-98.

58. Semple SJ, Patterson TL, Grant I. The context of sexual risk behavior among heterosexual methamphetamine users. Addict Behav. 2004;29(4): 807-10.

59. Maxwell JC. Emerging research on methamphetamine. Current Opinion Psychiatry. 2005;18(3):235-42

60. Lundqvist T. Cognitive consequences of cannabis use: comparison with abuse of stimulants and heroin with regard to attention, memory and executive functions. Pharmacol Biochem Behav. 2005; 81(2):319-30.

61. J-i I, Yamanashi K, Asakura T, Misu Y, Goshima Y. Differential effects of methamphetamine and cocaine on behavior and extracellular levels of dopamine and 3, 4-dihydroxyphenylalanine in the nucleus accumbens of conscious rats. Eur J Pharmacol. 2006;549(1-3):84-90.

62. Ernst $\mathrm{T}$, Chang L, Leonido-Yee M, Speck O. Evidence for long-term neurotoxicity associated with methamphetamine abuse: a 1H MRS study. Neurology. 2000;54(6):1344-9.

63. Gard C. METHAMPHETAMINE: Speeding Toward Psychosis. Current Health. 2004;30(5):25

64. Werb D, Kerr T, Zhang R, Montaner JS, Wood E. Methamphetamine use and malnutrition among street-involved youth. Harm Reduct J. 2010;7(1):5.

65. He J, Xie Y, Tao J, Su H, Wu W, Zou S, et al. Gender differences in sociodemographic and clinical characteristics of methamphetamine inpatients in a Chinese population. Drug Alcohol Depend. 2013:130(1-3):94-100.

66. Tsirigotis K. Gender differentiation of indirect self-destructiveness in drug addicted individuals (indirect self-destructiveness in addicted women and men). Psychiatric Q. 2019;90(2):371-83. 
67. Mansorian M. Solhi m, Dehdar T, Taghdisi MH. Hallucination experience in drug users: a qualitative study. J Iran Instit Health Sci Res. 2014; 13(14):467-75

68. Baggott MJ, Siegrist JD, Galloway GP, Robertson LC, Coyle JR, Mendelson JE. Investigating the mechanisms of hallucinogen-induced visions using 3, 4methylenedioxyamphetamine (MDA): a randomized controlled trial in humans. PLoS One. 2010;5(12):e14074.

69. Akiyama K. Longitudinal clinical course following pharmacological treatment of methamphetamine psychosis which persists after long-term abstinence. Ann N Y Acad Sci. 2006;1074(1):125-34.

70. Mahoney JJ III, Hawkins RY, De La Garza IIR, Kalechstein AD, Newton TF. Relationship between gender and psychotic symptoms in cocainedependent and methamphetamine-dependent participants. Gender Med. 2010;7(5):414-21.

\section{Publisher's Note}

Springer Nature remains neutral with regard to jurisdictional claims in published maps and institutional affiliations.

Ready to submit your research? Choose BMC and benefit from:

- fast, convenient online submission

- thorough peer review by experienced researchers in your field

- rapid publication on acceptance

- support for research data, including large and complex data types

- gold Open Access which fosters wider collaboration and increased citations

- maximum visibility for your research: over $100 \mathrm{M}$ website views per year

At $\mathrm{BMC}$, research is always in progress.

Learn more biomedcentral.com/submissions 